Open Access

\title{
Occupational interactions and income level: a social capital study using the first-order difference method
}

Weifeng Liu ${ }^{1 *}$, Yunsong Chen ${ }^{1}$ and Yanjie Bian²

* Correspondence:
phoenixlyu@gmail.com
'School of Social and Behavioral
Sciences, Nanjing University,
Nanjing University Xianlin Campus,
No.163, Xianlin Road, Qixia District,
Nanjing City, Jiangsu Province,
China
Full list of author information is
available at the end of the article

\begin{abstract}
This study aims to explore the impact of social resources within the workplace on individuals' income level among Chinese urban residents, using data provided by JSNET2009. To adequately address the endogeneity problem, we use the first-order difference method to help identify analysis models. The results indicate that: (1) both internal and outward interactions have positive effects on income level; (2) the effect of outward interactions is stronger than that of internal interactions; (3) the effect of outward interactions is stronger in the state-owned sector in comparison with the private sector. Our findingscontribute to the understandings of the causal effect of social capital.
\end{abstract}

Keywords: Social capital, Occupational interactions, First-order difference method, Internal interaction, Outward interaction

\section{Introduction}

Occupational interactions are important in the work and life of contemporary urbanites. On the one hand, production and consumption mechanisms in modern society determine that enterprises, governments, and social organizations are inextricably linked to each other. On the other hand, regardless of bureaucracy or flat management, interpersonal interactions centering on the working unit are an important and indispensable part of modern career life. From the perspective of social capital, interpersonal interactions, either inside or outside the work place, are able to bring opportunities for resource exchanges as well as building and maintaining of relationships to individuals in the workplace (Bian 2004). In addition, as social networks of occupational interactions are dependent on job and occupational demands, they are weaker than individual social networking based on friends, relatives, etc. in terms of individual selectivity and instrumentality. Their correlation to work, however, is much higher. The labor market effect of occupational interaction not only is, therefore, able to exert influences on individual labor market outcomes but also can be differentiated from functions of general individual social networking. This is worth further exploration.

In present studies on social capital in China, scholars focus on the impact of resources outside the workplace, such as relational networks of friends and family on 
individual labor market outcomes in the workplace (for relevant references obtained from the retrospective approach, please refer to Zhang et al. 2004; Zhang 2011a, 2011b; Chen and Fan 2011). However, analysis of social capital in the workplace concentrates in most cases in organization and management fields. There are only a few papers that focus on occupational social capital, and they are mostly limited to discussions about the relationship between leaders and subordinates. In addition, only cross-sectional data is adopted (Hao and Bian 2014; Liu et al. 2008; Li and Tu 2011; Han and Yang 2012). They are thus not persuasive enough in terms of casual inferences. This paper attempts to extend such a research scope in the field of quantitative study on social capital, to examine whether the relational network associated with the professional field domain has any influence on income for individuals in a workplace.

To inspect the casual relationship between social capital and individual labor market outcomes, potential endogeneity bias sources must be excluded by all means, such as individual heterogeneity (e.g., capacity, character), that can be neither observed nor considered (Mouw 2003, 2006; Chen and Fan 2010, 2011). In domestic studies, those employing a counterfactual framework and advanced econometric model to solve endogeneity problems keep emerging (Liang 2010; Chen 2012b; Chen et al. 2013, 2014; Chen and Bian 2015). Survey data from China, however, made available with sufficient sample size and information content and, of a size large enough to support counterfactual analysis, is still rare. A 2009 investigation on eight cities of China (JSNET2009) focuses on social networks; its questionnaire design is substantially extensible. Therefore, important data support can be offered by JSNET2009 to solve endogeneity problems among social capital analysis.

Based on JSNET2009 data, this paper also regards the urban workplace as its research site to analyze the casual effects between frequency of occupational interaction and worker income. For the purpose of solving endogeneity problems of general model regression, the first-order difference method is adopted based on the fixed effect hypothesis to eliminate individual heterogeneity, which fails to vary from the model with time, so that the real income effect of occupational interaction can be acquired. The structure of the content below is as follows. The first part is a review of the occupational interaction concept as social capital and relevant studies. In the second part, endogeneity problems are investigated, together with the corresponding solutions. Associated data and variables are introduced in the third part, and the fourth part describes and interprets model regression analysis results. Finally, in the fifth part, further analysis and summaries are presented.

\section{Occupational interaction: a social capital inside/outside the workplace} Theoretical context of occupational interaction

In a broad sense, occupational interaction refers to interpersonal interactions brought about by work and occupational demands. Occupational interaction, which serves as a critical component of individual social networks, exists in every workplace (Bian 2004). Relevant studies indicate that, just as in other individual social networks, structure and features of occupational interaction are under substantial influences from field domain (e.g., corporate organizational structure and environment) and individual positions (Han 1996; Carroll and Teo 1996; Lazega and Duijn, 1997; Cogliser and Schriesheim 
2000; Cole et al. 2002; Hao and Bian 2014). More importantly, as contact objects of occupational interaction hold resources of diverse natures and quantities, they may exert a great impact on individual labor market outcomes, just as is true of the social capital brought by relatives and friends. As a result, the occupational interaction process is also a process of social capital accumulation, mobilization, and use in the workplace (Bian 2004).

In the field of social capital studies, the theory that occupational interaction as a relationship characteristic affects labor market outcomes was first presented by Bian and Logan (1996). From a binary viewpoint of nation and market, power relationship interactions within an organization (e.g., by associating with superiors and leaders that represent hierarchical powers), market link interaction outside an organization (e.g., by associating with market main bodies out of the workplace), non-power interaction within an organization (e.g., having contact with technologies and machines instead of people), and so on were adopted to generalize types of occupational attributes. However, in conducting empirical research, different jobs were simply categorized into the three types mentioned above, and such a method appears to be slightly subjective. In subsequent studies, therefore, Bian (2004) officially put forward concepts of "Hierarchy Association" and "Markets Relationship" based on the 1999 Survey Data of five cities in China. In addition, Hierarchy Association and Markets Relationship are degrees with a series of occupational types that can be measured and treated as explanatory variables of social capital. Such a study provides concepts that operationalize occupational interaction theories of society in the transforming stage by comparing national and market forces.

On the basis of Bian's studies, analytical insights into occupational interaction can be thought of as position features of social networks, described by Hao and Bian (2014), who classify occupational interactions into outward, internal, and bridged connections, instead of the perspective of the nation-market forces. Among them, great heterogeneity exists between objects and actors of external connections as non-repetitive information can be offered to the latter. Regarding internal connections, objects and actors are significantly homogeneous; however, considering that they belong to an identical bureaucracy, related organizational resources are abundant. Bridged connections are similar to those of structural holes and across structural holes; not only can non-repetitive information be provided but also owns powerful organizational resources. Although trichotomy here fails to be carried out from a binary perspective of nation and market, it offers a perspective of occupational interaction observation for society in a transitional period together with other social situations. In this paper, by integrating analytical insights from Bian (2004) and Hao and Bian (2014), an occupational interaction concept of internal/external connections is adopted based on network locations, so as to analyze its influence on individual labor market outcomes.

\section{The function of occupational interaction}

In international sociology study circles, sociologists have been paying close attention to the impact of social networks on individual career development very early (Burt 1992, 2000; Meverson 1994; Podolny and Baron 1997; Kim 2001). Such research, however, emphasizes the measurement and analysis of network structures and in most cases 
focuses on social network location characteristics of occupational communicators instead of the direct measurement of occupational interactions as social capital. In the organizational management domain, relevant leader-member exchange (LMX) theory indicates that the closer the relationship between leaders and employees is, the higher the possibility that leaders will give priority to in-circle members (Law et al. 2000; Scandura and Schriesheim 1994). In addition, when the quality of interactions between leaders and members is high, it is more likely that the latter will obtain more resources, information, authorizations, etc. (Dienesch and Liden 1986). Leaders are even willing to assist members within the circle to formulate occupational planning and goals and take advantage of their own social networks to provide aid in objective fulfillment (Sparrowe and Liden 2005; Han 2010). In the case that the relationship between leaders and members is positive, or has a higher exchange quality, member career satisfaction also increases (Schriesheim et al. 1998; Wayne et al. 1999). At the same time, it is more probable that employees will achieve professional success ( $\mathrm{Ng}$ et al. 2005; Breland et al. 2007).

For studies in China, despite the fact that quantitative research in this domain originated with Bian et al. (Bian and Logan 1996; Bian 2004), the direct association between occupational interaction and labor market outcomes has not been analyzed specifically. Other scholars stress human relationships and the importance of social intercourse in particular workplaces. Some research conducted in English found that the leadermember relationship observed in China is similar to LMX in Western societies, although the former is usually extended to a close, private relationship outside of the workplace (Law et al. 2000). For example, according to the paternalistic leadership style in China (Cheng et al. 2002; 2004), leaders take particular care of subordinates who have a preferable relationship with them, and may even practice favoritism (Westwood and Chan 1992). Especially at times of failure or the unsoundness of formal organizational institutions, the exchange relation between superiors and subordinates turns into an alternative mechanism in such formal institutions to manage individual development (Peng and Heath 1996). As far as research in China is concerned, according to the findings of Ruan et al. (1990), the Chinese attach more importance to workplace-based karmic connection networks than do Westerners, which implies that occupational interaction has a special meaning for Chinese society. In line with Liu et al. (2008), by analyzing paired data of employees, colleagues, and direct leadership in manufacturing enterprises, it is found that the leader-member relationship has a significant influence on employee's career development prospects. For similar findings, please refer to psychological studies by $\mathrm{Li}$ and $\mathrm{Tu}$ (2011), as well as management research conducted by Han and Yang (2012). In addition to this, studies on the floating population indicate that the professional network has a special value for migrants, especially migrant workers (Li 1996; Liu 2001; Cao 2003).

Nevertheless, the relevant international and Chinese research mentioned above not only is limited in number but also suffers from three limitations. First, studies on occupational interaction only explore the leader-member relationship. As described above, occupational interaction does not simply refer to the connection between workers and leaders; it should also include communications between hierarchy leaders and colleagues within a workplace, as well as interactions with staff from other workplaces. Second, all the above literature adopts cross-sectional data ${ }^{1}$ without taking endogeneity 
problems in social capital into account. In other words, while personal abilities (including character and extroversion) may influence both occupational interactions and career development, it is possible that a reciprocal causation relation exists between the situation of career and workplace social capital. Therefore, statistical correlation found by empirical analysis cannot be employed to prove without a doubt that occupational interaction has a causal influence on career development. Third, previous research fails to emphasize differences in occupational interaction and traditional social capital based on affinity (relatives, friends, etc.). Furthermore, such network component differences may lead to a phenomenon whereby both are provided with diverse features at the time of exerting labor market effects.

\section{Concepts of internal/outward occupational interactions}

As mentioned above, the concept of occupational interactions can be operationalized from different perspectives. In terms of feature analysis on intercourse objects, it can be divided into Hierarchy Association and Markets Relationship (Bian and Logan 1996; Bian 2004). But, if analyzed based on the relative location of social networks, it is otherwise categorized as internal/outward associations, etc. (Hao and Bian 2014). In this paper, the concept of occupational interaction is operationalized as the continuation of the location viewpoint described by Hao and Bian (2014). However, it is important to improve on the three types of measurements for occupational interactions.

First, it is irrational to adopt interaction frequencies with clients, service objects, and customers or with different kinds of guests. For example, interaction frequency between workers in service jobs and clients/customers is significantly higher than for employees in managerial posts and so thus may only reflect differences in positions and even the higher frequency-associated disadvantages in job characteristics. After preliminary testing of JSNET2009 data, it is found that, after controlling for profession, interaction frequency with clients/customers has a significant negative correlation to incomes and job levels (among other factors) of workers. Such a result supports our speculations. Interactions with clients/customers may only embody job characteristics in the secondary labor market. Second, "bridged connection" is defined as interactions with agents of other units and organizations, according to Hao and Bian (2014). However, the corresponding measurement becomes interaction with other units (hierarchy departments/ units and other departments) without stressing the "agents". Consequently, what were described as bridged connections in early studies is deemed to be reflections of "outward connections" in most cases.

In this paper, a binary method of "internal interaction" and "outward interaction" is presented and adopted. Here, we emphasize that internal interaction in a workplace refers to interpersonal interactions inside the unit, while an outward interaction in a workplace consists of interpersonal interactions performed outside of the workplace due to job demands. Both internal and outward interactions are specially carried out as a result of professions and jobs; their differences lie in interactions with relatives and friends in a general sense. To a certain extent, the homogeneity of internal interaction is obvious; in comparison, outward interactions can be involved with more extensive organizational resources and even give rise to connections similar to structural holes and across structural holes (Hao and Bian 2014). 
It is worth noting that the internal interaction and outward interaction concepts utilized for the workplace are related to the concept of homophilous resources presented in the latest international literature, although they differ from each other in essence. According to Chen and Volker (2016), under the market economy condition, patrons and job seekers with the "same post" (or in the same trade) are able to intensify pull effects of social capital on incomes, status, etc. That is, the homogeneity of "having the same post" will enlarge the effect of social capital. In terms of the internal interaction in a workplace proposed here, it largely belongs to the category of having the same post. What it measures, however, is not a single patron but the intercourse object of the entire unit. With regard to outward interaction, it not only covers those of the same post from diverse units but also consists of those from different posts and units. It is also about measurements at the group level, rather than the individual level.

\section{Three hypotheses of occupational interaction}

For internal and outward interactions, the social resources of others can theoretically be brought to individuals through occupational interactions. Both, therefore, can be classified into "available social capital," ${ }^{2}$ which is the "network social capital" defined by Mouw (2003) or the "possessive social capital" described by Zhao (1998). In spite of the different language, those concepts all stand for the sum total of potential social capital embedded in a given egocentric network (Chen and Fan 2011). From the viewpoint of occupational interaction element features, objects of occupational interactions reflect the network structure of laborers in the field domain of work, while the frequency of interaction signifies the possibility for laborers to retrieve resources from the network structure (Bian 2004).

In conformity with market transition theory, thanks to the transformation from planned economy to market economy, the human capital ROI of China gradually increases while the rate of return for political capital gradually decreases (Nee 1989). By contrast, much of the literature emphasizes that China's social transformation is a process of double intensification including reallocation and market mechanisms reflected in the simultaneous increase in return on revenue for political and human capital, instead of an inversely proportional relationship (Walder 1995; Bian and Logan 1996). In China, human relationships, social networks, and interpersonal interactions are usually the main approaches to bearing, providing, and drawing support from the redistribution of power, which is also known as political resource (Akos 1994; Lin 1995). In this way, the higher the resource content of a social network, the greater the income returns that accumulate will be (Bian and Zhang 2001). On this basis, we speculate that, as a special social capital, the value of occupational interaction in cities will continue to have the ability to absorb external resources for the long term. Based on the above theories and the large corpus of empirical literature about the social capital labor market (see Zhang et al. 2004; Zhang, 2011a; Chen and Fan 2011), we propose hypothesis 1 .

Hypothesis 1: Both internal and outward interaction in workplaces contribute to personal income improvement for urban residents.

As mentioned above, outward interaction brings external social resources from other units. Compared with internal interaction, therefore, its resources have greater 
heterogeneity. In other words, external resources represent a higher power range as well as non-redundant and updated work information (Lin 2008). Thus, it can be further speculated that influences of outward interaction on labor market outcomes should be stronger than internal interaction. From this, hypothesis 2 is presented below.

Hypothesis 2: Internal interaction in the workplace has less influence on income than outward interaction.

According to the findings of Zhang and Cheng (2012), the degree of marketization is able to reduce income effects of potential social capital (attributes such as the upper bound or span of individual social networking, including the New Year Greeting Network $^{3}$ ) and mobilized social network capital (e.g., social intercourse on catering). In other words, the higher the degree of marketization, the weaker the effect of social capital. However, as has been mentioned at the very beginning, occupational interactions are different from individual social capital (Chinese New Year Greeting Network; catering network) based on social relationships such as friends and relatives. The relevant reason is that social ties of occupational contacts are established dependent on job demands and post settings, during which self-selectivity will not be too strong (for nonrandom literatures related to social networks, please see Mouw 2006; McPherson et al. 2001). With this in mind, the degree of "personalization" and "instrumentality" of information and resources transferred by them may become even lower. When compared with social resources based on intimacy networks, however, occupational interaction brings more "specialized" information centering on professional posts or has more influence. In this way, we predict that in departments where the degree of marketization is high, occupational interaction will give rise to stronger effects. Otherwise, in governments and state-owned enterprises with a low degree of marketization, such effects are insignificant. On this basis, hypothesis 3 is put forward.

Hypothesis 3: The influence of occupational interaction on income will be stronger in non-state sectors.

\section{Omitting variables: causal inference strategy}

The problem of endogeneity is a key bottleneck to social capital studies (Mouw 2003, 2006). Chen and Fan (2010) generalize four sources of endogeneity bias in quantitative studies of sociology: omitted variable bias, self-selection bias, sample selection bias, and simultaneity bias. In line with the categorization method of Chen and Fan (2011), the influences of occupational interaction on which we focus on individual results fall into the category of ectogony of "accessed social capital". The endogeneity problem in this category is mainly about omitting variables of ability. ${ }^{5}$ That is, it is possible for personal ability (e.g., character and extroversion) to determine occupational interaction and income level at the same time. Considering that abilities are usually implicit and cannot be observed, standard single equation linear regression (e.g., the OLS model of the least square method) or nonlinear regression (e.g., the Logit model) can lead to bias due to the omission of variables. In existing studies on accessed social capital, overseas scholars often adopt the fixed effect model and instrumental variables to solve such issues (Yakubovich 2005; Munshi 2003; Beaman 2008). By contrast, for social capital researching China, causal analysis on accessed social capital based on a counter-factual framework is work that remains to be completed. 
In this paper, this problem is resolved by the first-order difference method based on the assumption of fixed effect. Relying on differences between the independent variable and the dependent variable of an identical respondent in the time dimension, the difference method is adopted to eliminate time-invariant factors other than observations, also known as heterogeneous disturbance items, including personal ability. It is assumed that two-period private data is offered, in which case we can acquire data about "present job" and "first job". First, the corresponding regression equation can be written as follows:

$$
Y_{i}=\beta_{0}+\beta_{1} X_{i}+\alpha_{i}+\varepsilon_{i}
$$

where $Y_{i}$ refers to individual labor market outcomes such as occupational status or the income of a respondent ranking $i, X_{i}$ to vector quantity of a group of exogenous control variables, and $\alpha_{i}$ to respondent heterogeneity that cannot be achieved in physical operations and is regarded as a fixed factor that fails to change with time. The remaining $\varepsilon_{i}$ denotes the stochastic error term; $X_{i}$ and $\varepsilon_{i}$ are both factors that are able to vary with time.

At two different time points $t$ and $t-1$, regression equations are

$$
\begin{aligned}
& Y_{i t}=\beta_{0 t}+\beta_{1} X_{i t}+\alpha_{i t}+\varepsilon_{i t} \\
& Y_{i(t-1)}=\beta_{0(t-1)}+\beta_{1} X_{i(t-1)}+\alpha_{i(t-1)}+\varepsilon_{i(t-1)}
\end{aligned}
$$

As just mentioned, $\alpha_{i}$ is the heterogeneity of the respondent and is seen as a fixed factor unchanged with time. Hence, in this model, it is assumed that $\alpha_{i t}=\alpha_{i(t-1)}$. Equation (2) is then subtracted from Eq. (3) to obtain the following formula:

$$
\Delta Y_{i}=\beta_{0}+\beta_{1} \Delta X_{i}+\Delta \varepsilon_{i}
$$

As presented above, through equation subtraction, respondent heterogeneity $\alpha_{i}$ (such as personal ability that cannot be obtained by practical operations) is removed by means of difference. Under the circumstance that $\varepsilon_{i t}$ is irrelevant to $\varepsilon_{i(t-1)}$, unbiased estimation is carried out for Eq. (4) based on OLS.

\section{Data variables: first job and present job}

The data for this paper is derived from JSNET2009, initiated by Bian Yanjie ${ }^{6}$ and carried out from June to October in 2009 in eight cities including Guangzhou, Shanghai, Xi'an, Tianjin, Lanzhou, Xiamen, Ji'nan, and Changchun. According to the requirements of a multi-layered model, JSNET2009 acquired samples of 7102 residents with non-farm work experience with an age range from 18 to 69. The investigation covered multiple social capital and social networking subjects, such as personal information, job-seeking process, discussion networks, the Chinese New Year Greeting Network, social participation, and social trust. More importantly, data was collected on personal details and labor characteristics for respondents about first and present jobs by means of a questionnaire. First job and present job, as described here, do not signify that workers must have experiences in changing jobs; even though no workplace variation exists, their posts and occupational labor characteristics both change with time, as is recorded by responses to the questionnaire. In addition, in the same post, occupational interaction changes at a specific point of time may lead to differences in individual 
income. Among those sample residents, therefore, some changed jobs, while others did not, which is not the same as differential analysis in job-seeking process studies that focus on the crowd as samples of job changing.

It is very likely for missing values to appear during the collection of multi-phase data with the same subject, and this frequently leads to problems such as small sample sizes and under-representation. As a result, differential analysis has a higher requirement for samples. Given this, the first-order difference analysis in this paper is carried out in two steps based on samples of diverse sizes. The first step is the "benchmark difference model"; based on the typical Mincerian earnings model, it predicts incomes by basic demographic characteristics, investment in human capital, and experience. In a difference model, control variables such as political status, job-seeking methods, and work experience (the number of job changes) that vary with time are controlled for. In comparison, sex (which does not change with time) and a disturbance item of personal ability omitted by the model are both removed by means of difference. Please note that the sample size adopted by the benchmark difference model is up to 6263 (88\% in the total sample size of 7102) and they form 12,526 observed values. The second step is the establishment of the "precise difference model". To make analysis results more reliable, more precise variables of work experience (age) and human capital (education degree is permitted to change with time) are employed, together with controls over organization variables (including company type, unit size, and occupation categories) that may vary with time. The sample size used by this model is 2536, and 5072 observed values are correspondingly constituted. Due to the existence of missing values, despite the fact that the sample size of the precise difference model is approximately half of the benchmark difference model, this is still a fixed effect model of the maximum sample size relative to other social capital studies in China. More importantly, as long as the estimation results of such two models are consistent, it can be deemed that sample incompleteness exerts no substantial influence on the results of this paper. Relevant variable descriptions are respectively performed specific to the two models.

\section{Dependent variable}

This paper focuses on the impact of social capital that laborers can access and its impact on labor market outcomes. On this basis, the dependent variable is the respondent's monthly income. The section referring to "Professional History" in the JSNET questionnaire gathers information about the respondent's annual income for his/her first job. Pre-tax income for all of the respondent's current jobs are investigated in the section entitled "Work, Income and Welfare," which also gathers information on bonuses other than monthly income and wages as well as other earnings, year-end bonus, etc. After the year-end bonus is divided by 12 to obtain average monthly income, incomes of such three terms (monthly income, bonuses, other earnings, and year-end bonus) are added together, and the result serves as the respondent's income from his/ her present job.

Respondents' first job and present job cover a large span, with the longest interval being 53 years. Using direct difference in incomes from different years is obviously inappropriate, because various factors such as inflation must be taken into account. Therefore, we computerize the consumer price index (CPI) coefficient for each year, 
with 1951 as the base year (the CPI on 1951 is set as 100). To be precise, the year that corresponds to income for first job is set as the last year of this first job. In the case the respondent never changed jobs and has retired, the corresponding year is set as the year of retirement. If he/she has neither changed jobs nor retired, the corresponding year is set to 2008 (because the data was collected in 2009). The corresponding year for respondents who changed jobs for the first time in 2009 is still set as 2008. For present job, which refers to those who are working, income corresponds to income for 2008; but if the respondent has retired, the corresponding year should be set as the year when they left or retired. Similarly, the year corresponding to respondents whose departure or retirement occurred in 2009 is also set as 2008. In this manner, after converting each sample, comparable income with a benchmark of 1951 is acquired. Finally, due to income skewness, logarithm transformations are conducted for relevant incomes.

Considering that the overall income level has gone up since the reform and openingup policy was carried out, except for CPI corrections, adjustments in robustness testing are based on national urban workers' average income level over the years presented in China Compendium of Statistics and China Statistical Yearbook. The average monthly earnings of urban workers in the corresponding province is subtracted from the monthly income data acquired through questionnaires, which signifies that relative income is adopted as the dependent variable to carry out the tests. As our data is from eight cities, and data from the Yearbook uses the province as the unit, such a relative income approach may take in noise. However, it is found that analysis based on CPI calibration and province average wage calibration achieves identical conclusions. ${ }^{7}$

\section{Occupational interaction}

Occupational interaction is the core independent variable in this paper. Data here is derived from measurements on interaction frequencies among respondents and contact objects in work field domain adopted by the questionnaire. Interaction frequencies measured by the questionnaire are classified into "often," "sometimes," "rarely," and "never," scoring 4, 3, 2, and 1, respectively. After adding up interaction frequencies between respondents and personnel in the same unit (superior leaders, junior colleagues, and peer colleagues), the concrete value of internal interactions is obtained. In the same way, through the addition of interaction frequencies with personnel from other units (superior department/unit, subordinate departments/units, and other units), we achieve the value of outward interactions. Please note that, whether internal interaction or outward interaction, child pointers (such as superiors, subordinates, and peer intercourse) are added together instead of carrying out a separate analysis. The reason for this is that independent interactions between superiors and subordinates may stand for seniority and power rank. For instance, inside a unit where leaders have more contacts with subordinates, interaction frequencies among diverse hierarchies can be adopted to avoid such a problem, to directly manifest resources generated by occupational interaction frequencies. ${ }^{8}$ In addition, the missing value of occupation interaction variable is processed as follows. If an answer to any of the six questions in the questionnaire is missing, the respondent will be removed from the final analysis sample. Occupational interaction data related to respondent's first job and present job (first occupation and the last occupation) are collected by means of questionnaire. 


\section{Control variable}

Control variables for this research consist of demographic characteristics, unit characteristics, and occupational stigma.

\section{Demographic characteristics}

Fundamental demographic characteristics and human capital variables of respondents are constituted by their sex, age, education level, political status, the number of units the respondents have worked at, etc. In detail, while sex and political status serve as dichotomous dummy variables $(M=1$; party member $=1)$, the age variable describes the age at which laborers began their first or present job, and education level is a continuous variable. ${ }^{9}$ Moreover, the square of age is also incorporated into the model.

\section{Unit characteristics}

Unit characteristics include the size and nature of the work unit, as well as the job title/technical level and category of employment. Among them, the size of unit refers to the number of staff in the unit, which may be simultaneously associated with occupational interaction frequencies and income. Similarly, unit nature is also taken into consideration and is set as a dichotomous variable. Finally, classified into two categories of state-owned sectors and non-state sectors, the latter is used as a reference group with the value of 0 , while the former is 1 .

\section{Occupational stigma}

In the part of benchmark model, the frequency of job changes is adopted to serve as substitution variable for work experience. During the first job, this frequency is set as 1 uniformly; however, for the present job, the frequency is the actual job changing frequencies of the respondents. In addition, the process by which laborers begin their first or present job is also considered. There are seven approaches to entering the workplace that are identified in the questionnaire: recommendation, individual application, government distribution, government distribution and recommendation, individual application and recommendation, government distribution and replacing parents, and other. "Other" is set as a missing value. All approaches containing the element of "recommendation" are merged into the category of "pulling strings," while the remaining ones are classified as "not pulling strings". In this way, approaches to entering the workplace are divided into two categories: pulling string and not pulling string. While the latter is used as the reference group, values for it and the former are set as 0 and 1 , respectively. Concerning the precise model, the category of employment is under further control. Among ten occupations provided in the questionnaire (professionals; head of organizations and units; head of public institutions; head of enterprises; office clerks; commercial staff; service providers; agriculture; people in forestry, animal husbandry, and fishery industry; industrial workers; and unclassified careers), professionals are adopted as the reference group and endowed with a value of 0 , and the other occupations are treated as nine dummy variables through processing. Job title and technical level are both investigated in the questionnaire. They are treated as dichotomous dummy variables, with personnel without technical levels (or unskilled occupations) serving as the reference group (value $=1$ ). Furthermore, medium-grade professional titles and advanced technical job titles are combined into administrative staff and given the value of 1 . 


\section{Analysis and results}

Empirical analysis of this research is carried out in three steps. First, the sample of 6263 people is described and analyzed based on the benchmark difference model. Second, the other sample of 2536 people is also illustrated to perform precise difference model analysis. Thirdly, as mentioned in the discussion in literature review, it is widely believed in the academia that the degree of marketization has an influence on the market effect of social capital. Therefore, if market effects of occupational interaction are verified, the performance of occupational interactions in organizations of diverse marketization degrees should be investigated continuously. Thus, interaction item analysis is further conducted to study whether attributes of state ownership and nonstate ownership have any impact on functions of occupational interaction.

\section{Benchmark difference model analysis}

In the first place, the analysis described in the first step was performed. Basic descriptions of relevant key variables are given below (see Table 1).

According to Table 1, changes in fundamental information of laborers from first job to present job can be found. First, the mean value (logarithm) of monthly income (dependent variable) increases by 0.733 , and its standard deviation goes up to 0.772 from 0.653 , which indicates that after job changing, the income of this laborer rises on the whole in spite of an increasingly larger income gap. ${ }^{10}$ In terms of occupational interaction, both internally and outwardly, the present job has a better performance than the first job. Considering increases in the overall mean value and the standard deviation, the gaps of occupational interaction are becoming greater. In addition, variations in variable values of work experience, political status, way of gaining entry to work, etc. also show that, from first job to the present job, a lot of changes occur to affect the overall characteristics of laborers. Can such variations exert influence on market outcomes for laborers? If yes, what are the influences? Subsequently, key variables were controlled to perform regression analysis. The results are presented in Table 2.

In model 1 of Table 2, the OLS method is used to estimate the influence of occupational interactions among samples on the incomes of a first job. While the bias coefficient of internal interaction is -0.005 , an insignificant negative number, that of outward interaction, is 0.051 , which is very significant compared with a statistical level of 0.001 .

Table 1 Basic descriptions of data $N=6263$

\begin{tabular}{|c|c|c|c|c|}
\hline \multirow[t]{2}{*}{ Variables } & \multicolumn{2}{|l|}{ First job } & \multicolumn{2}{|l|}{ Present job } \\
\hline & Mean value & Standard deviation & Mean value & Standard deviation \\
\hline Monthly income (taking the logarithm) & .575 & .653 & 1.308 & .772 \\
\hline Internal interaction & 8.943 & 2.322 & 9.108 & 2.502 \\
\hline Outward interaction & 5.749 & 2.801 & 6.309 & 3.023 \\
\hline \multirow[t]{2}{*}{ Frequency of job changes } & 1 & 0 & 1.340 & 1.987 \\
\hline & $N$ & $\%$ & $N$ & $\%$ \\
\hline Male & 3353 & 53.54 & - & - \\
\hline Party member & 247 & 3.94 & 978 & 15.62 \\
\hline Seeking job by pulling strings & 1276 & 20.37 & 1444 & 23.06 \\
\hline
\end{tabular}


Table 2 Income effects of occupational interaction based on the benchmark difference model

\begin{tabular}{|c|c|c|c|}
\hline \multirow[t]{2}{*}{ Variables } & \multicolumn{2}{|c|}{ Least square method model } & \multirow{2}{*}{$\begin{array}{l}\text { First-order difference } \\
\text { model } \\
\text { M3 }\end{array}$} \\
\hline & M1 & M2 & \\
\hline Explanatory variable & $\begin{array}{l}\text { Monthly income of first } \\
\text { job }\end{array}$ & $\begin{array}{l}\text { Monthly income of present } \\
\text { job }\end{array}$ & $\begin{array}{l}\text { Monthly income } \\
\text { difference }\end{array}$ \\
\hline \multirow[t]{2}{*}{ Internal interaction } & -.005 & .010 & $.012^{*}$ \\
\hline & $(.004)$ & $(.008)$ & $(.004)$ \\
\hline \multirow[t]{2}{*}{ Outward interaction } & $.051^{* * *}$ & $.057^{* *}$ & $.031^{* *}$ \\
\hline & $(.008)$ & $(.013)$ & $(.007)$ \\
\hline \multirow{2}{*}{$\begin{array}{l}\text { Seeking job by pulling } \\
\text { strings }\end{array}$} & $.234^{* * *}$ & .012 & .053 \\
\hline & $(.041)$ & $(.034)$ & $(.032)$ \\
\hline \multirow[t]{2}{*}{ Male } & $-.084^{* *}$ & $-.139^{* *}$ & - \\
\hline & $(.023)$ & $(.032)$ & - \\
\hline \multirow[t]{2}{*}{ Party member } & $.431^{* * *}$ & $.152^{* *}$ & $.345^{* * *}$ \\
\hline & $(.049)$ & $(.034)$ & $(.044)$ \\
\hline \multirow[t]{2}{*}{ Frequency of job changes } & - & .018 & .023 \\
\hline & - & $(.009)$ & $(.013)$ \\
\hline \multirow[t]{2}{*}{ Intercept } & $.304^{* * *}$ & $.874^{* * *}$ & $.664^{* * *}$ \\
\hline & $(.050)$ & $(.083)$ & $(.050)$ \\
\hline$R$ square & .094 & .092 & .033 \\
\hline Sample size & 6263 & 6263 & 6263 \\
\hline
\end{tabular}

Note: (1) ${ }^{*} p<0.05,{ }^{* *} p<0.01,{ }^{* * *} p<0.001$. (2) Values inside the parentheses are standard errors obtained by taking heteroskedasticity robustness and urban cluster robustness into account. (3) In a difference mode, what an explanatory variable corresponds to is the change value. For the conciseness of the table, different numerical values of dummy variables such as unit nature, way of gaining entry to work and occupation, etc. are processed as continuous variables. In a logical sense, their establishments do not signify specific meanings. For example, variables for the way of gaining entry to work are $-1,0$, and 1 , standing for variation from pulling strings to not pulling strings, being invariant, and from not pulling strings to pulling strings, separately. Therefore, it represents the degree of "changing as pulling strings" in practice. In robustness analysis, original dummy variables are adopted to perform tests and highly consistent results are achieved

In model 2, such influences are estimated by the same method. It turns out that the bias coefficient of internal interaction is still insignificant, as it is only 0.010 , although this is significant for outward interaction (0.057) which is also based on a statistical level of 0.01. It is clear that in an OLS model, internal interactions of laborers seem to have no significant impact on income and outward interactions play a positive role on stabilization. Nevertheless, as pointed out above, due to potential endogeneity problems, the results of single-period regression are not credible.

For model 3 in Table 2, the first-order difference method is utilized to estimate that the bias coefficient of interaction is 0.012 and 0.031 for outward interactions. Both are significant at a statistical level of 0.05 or 0.01 . In line with differential analysis results, one unit of increase in internal interaction variations gives rise to a $1.2 \%$ increase in income $\left(\approx e^{0.012}-1\right)$. For outward interaction, when it increases by one unit, the corresponding income will go up by $3.1 \%\left(\approx e^{0.031}-1\right)$. If it is believed that individual heterogeneity is stable when a laborer goes from his/her first job to his/her present job, occupational interactions are deemed to have a certain and positive influence on the income of laborers. Additionally, the influence of outward interactions is almost three times larger than that of internal interactions. In this manner, hypotheses 1 and 2 are both verified preliminarily. 
Except for occupational interactions, the impact of other variables on laborer market outcomes is also analyzed based on mode. In model 3, individual heterogeneity is eliminated from the model by means of difference, so that the way of seeking a job is no longer significant. According to Chen et al. (2013), data from CHIPS2002 is utilized to analyze whether pulling string affects income, and their results also show, using firstorder difference model, that the coefficient of the way of seeking job is insignificant. This is consistent with the findings from this paper, and it is also discovered that the work experience of laborers does not exert any significant facilitation influence on the relevant market outcomes, while political status has a very robust positive effect.

\section{Precise difference model}

To guarantee that the data analysis results are reliable, tests are performed at the second step. More control variables are incorporated, including the adoption of the age of the laborer as an experience agent and allowing for changes to education level with time (that is, considering in-service education). Meanwhile, multiple occupational and unit characteristic variables, such as unit nature, unit size, category of employment, and supervisory level, are also further controlled. The sample is thus downsized to 2536. The relevant basic data is presented in Table 3.

The sample size for a precise model in Table 3 is far smaller than that of the benchmark model shown in Table 1, in spite of their population distributions being extremely close. For example, in Table 3, the mean value for monthly income (dependent variable and taking logarithm) at the first job stage is 0.564 , with a standard deviation of 0.535 . For the present job, mean value and standard deviation are 1.375 and 0.772 , respectively. In comparison, they are respectively 0.575 and 0.653 for the first job, and 1.308 and 0.772 for the present job, as presented in Table 1 of the benchmark model sample. It can be seen that there is a minor gap between the basic statistics of monthly incomes based on the two samples. In terms of the main explanatory variables, the mean values of internal and outward interactions during the first job are 9.003 and 5.786, respectively, in Table 3, which closely follows those of the benchmark model (8.943 and 5.749,

Table 3 Basic data descriptions $N=2536$

\begin{tabular}{|c|c|c|c|c|}
\hline \multirow[t]{2}{*}{ Variables } & \multicolumn{2}{|c|}{ First job } & \multicolumn{2}{|c|}{ Present job } \\
\hline & Mean & St.d & & Mean \\
\hline Monthly income (logarithm) & .564 & .535 & 1.375 & .772 \\
\hline Internal interaction & 9.003 & 2.287 & 9.137 & 2.563 \\
\hline Outward interaction & 5.786 & 2.785 & 6.625 & 3.090 \\
\hline Age & 20.358 & 3.803 & 31.859 & 8.679 \\
\hline Education level & 12.194 & 2.869 & 12.514 & 3.013 \\
\hline \multirow[t]{2}{*}{ Number of people } & 5.357 & 2.180 & 4.574 & 2.235 \\
\hline & $N$ & $\%$ & $N$ & $\%$ \\
\hline Male & 1302 & 51.34 & - & - \\
\hline Party member & 74 & 2.92 & 260 & 10.26 \\
\hline State-owned unit & 1608 & 63.41 & 1168 & 46.06 \\
\hline Administrative staff & 869 & 34.27 & 1008 & 39.75 \\
\hline Seeking job by pulling strings & 649 & 25.59 & 786 & 30.99 \\
\hline
\end{tabular}


respectively). For the present job stage, however, the mean values of internal and outward interactions are 9.137 and 6.625, respectively. They are very close to the mean values for the benchmark model, which are 9.108 and 6.309, respectively. Standard deviations between the two model samples are not substantially different. By comparison, it can be found that no great difference exists among the basic statistics of the core variables in the samples for the two models. As far as variables such as sex, political status, and gaining entry to work are concerned, there are some differences between the two samples. Generally, however, they are nearly identical and thus no longer examined here.

In the samples given in Table 3, from the first job to the present job, the average age of laborers increases by 11.501 years. The education level, however, only goes up by 0.320 per year. It is obvious that most laborers do not undertake further education after they enter the labor market. The downsizing of the average unit size indicates that, after the transition to the market economy, many laborers flowed into units of smaller scale. Practically, the number of people working in state-owned sectors drops by 440 , that is, by about $17 \%$. As in Table 1, the overall characteristics of laborers from the first job to the present job show enormous change. Analysis results of the precise difference model are referred to next (see Table 4), in order to address the influence of such changes on laborers' market outcomes.

First of all, emphasis is placed on the influence of occupational interaction on income. Clearly, the cause-effect patterns in Tables 2 and 4 are almost uniform. In other words, the bias coefficient of internal interaction variation fails the significance test during single-period analysis for first and present job stages; otherwise, the coefficient in the difference model is significant. Comparatively, variations of outward interaction are all significant in the three models, and their bias coefficients are positive. In the difference model (model 3), bias coefficients for internal and outward interaction changes are 0.008 and 0.016 , respectively. Namely, one unit of increase in internal interaction variations gives rise to $0.8 \%$ rise of income $\left(\approx e^{0.008}-1\right)$. When outward interaction increases one unit, the corresponding income increases by $1.6 \%\left(\approx e^{0.016}-1\right)$. Both the benchmark model based on sample size of over 6000 and the precise difference model based on sample size of over 2000 achieve consistent results. On the one hand, internal and outward interactions are both beneficial to the improvement in income; on the other hand, relative to the outward interaction, the internal has a stronger promoting function. On this basis, hypotheses 1 and 2 are proved correct.

\section{Marketization discrepancies in the rate of return of occupational interaction}

Two interaction items are respectively added into the income models of the first job, the present job, and the first-order difference: the interaction item of internal interaction and the state-owned sector and the interaction item of outward interaction and the state-owned sector. Analysis results are given in Table 5. It is found that after the addition of such interaction items to first job, present job, or difference model, the coefficient of the interaction item of internal interaction and the state-owned sector is insignificant. However, concerning the models of present job and difference, the interaction item for outward interaction (or variation) and the state-owned sector passes the significance testing with a statistical level of 0.05 . The corresponding coefficient is a 
Table 4 Income effects of occupational interaction based on the precise difference model $N=2536$

\begin{tabular}{|c|c|c|c|}
\hline \multirow[t]{2}{*}{ Variable } & \multicolumn{2}{|c|}{ Least square method model } & \multirow{2}{*}{$\begin{array}{l}\text { First-order difference } \\
\text { model } \\
\text { M3 }\end{array}$} \\
\hline & M1 & $\mathrm{M} 2$ & \\
\hline Explanatory variable & $\begin{array}{l}\text { Monthly income of } \\
\text { first job }\end{array}$ & $\begin{array}{l}\text { Monthly income of } \\
\text { present job }\end{array}$ & $\begin{array}{l}\text { Monthly income } \\
\text { difference }\end{array}$ \\
\hline \multirow[t]{2}{*}{ Internal interaction } & -.001 & -.012 & $.008^{*}$ \\
\hline & $(.004)$ & $(.013)$ & $(.003)$ \\
\hline \multirow[t]{2}{*}{ Outward interaction } & $.018^{* *}$ & $.033^{*}$ & $.016^{*}$ \\
\hline & $(.004)$ & $(.011)$ & $(.005)$ \\
\hline \multirow[t]{2}{*}{ Seeking job by pulling strings } & $.098^{* * *}$ & .014 & .034 \\
\hline & $(.017)$ & $(.051)$ & $(.036)$ \\
\hline \multirow[t]{2}{*}{ Male } & $-.078^{* *}$ & $-.120^{* *}$ & - \\
\hline & $(.017)$ & $(.032)$ & - \\
\hline \multirow[t]{2}{*}{ Age } & .003 & .003 & $.029^{* *}$ \\
\hline & $(.011)$ & $(.009)$ & $(.007)$ \\
\hline \multirow[t]{2}{*}{ Square of age/100 } & .020 & -.017 & $-.029^{*}$ \\
\hline & $(.026)$ & $(.014)$ & $(.010)$ \\
\hline \multirow[t]{2}{*}{ Education level } & $.044^{* * *}$ & $.059^{* * *}$ & $.08^{* * *}$ \\
\hline & $(.004)$ & $(.008)$ & $(.01)$ \\
\hline \multirow[t]{2}{*}{ Party member } & 089 & $.133^{*}$ & $.269^{* *}$ \\
\hline & $(.058)$ & $(.046)$ & $(.061)$ \\
\hline \multirow[t]{2}{*}{ Frequency of job changes } & - & .006 & .011 \\
\hline & - & $(.011)$ & $(.013)$ \\
\hline \multirow[t]{2}{*}{ State-owned unit } & $-.453^{* * *}$ & $-.207^{* * *}$ & $-.178^{* * *}$ \\
\hline & $(.043)$ & $(.037)$ & $(.01)$ \\
\hline \multirow[t]{2}{*}{ Unit size/100 } & -.001 & .005 & .001 \\
\hline & $(.001)$ & $(.005)$ & $(.009)$ \\
\hline \multirow[t]{2}{*}{ Administrative staff } & $.083^{*}$ & $.187^{* *}$ & $.179^{* * *}$ \\
\hline & $(.029)$ & $(.036)$ & $(.032)$ \\
\hline $\begin{array}{l}\text { Category of employment (10 } \\
\text { categories) }\end{array}$ & Yes & Yes & No \\
\hline \multirow[t]{2}{*}{ Intercept } & .091 & $.789^{*}$ & $.884^{* *}$ \\
\hline & $(.164)$ & $(.247)$ & (.197) \\
\hline$R$ square & .398 & .224 & .107 \\
\hline Sample size & 2536 & 2536 & 2536 \\
\hline
\end{tabular}

Note: (1) ${ }^{*} p<0.05,{ }^{* *} p<0.01,{ }^{* * *} p<0.001$. (2) Values inside the parentheses are standard errors obtained by taking heteroskedasticity robustness and urban cluster robustness into account. (3) "Yes" means this variable is controlled for in the model. (4) Similar to Table 3, in a different mode, what an explanatory variable corresponds to is the change value. For the conciseness of the table, different numerical values of dummy variables such as unit nature, way of gaining entry to work and occupation, etc. are processed as continuous variables. In a logical sense, they do signify specific meanings. For example, variables for unit nature are $-1,0$, and 1 , and these represent variation between state-owned and privately owned sectors, which are invariant, and between privately owned and state-owned, respectively. Therefore, if seen as a continuous variable, the difference in the nature of the unit represents the degree of "becoming state-owned" in practice. In robustness analysis, original dummy variables are adopted to perform tests and highly consistent results are achieved

negative number. This indicates that the influences of outward interaction on incomes in the state-owned sectors are minor, while being rather large for non-state departments.

Specifically, according to the present job model, the effect of outward interaction on the non-state sector has a value of 0.047 , while it is only 0.015 for state-owned sectors 
Table 5 Interaction model between occupational interaction and unit nature $N=2536$

\begin{tabular}{|c|c|c|c|}
\hline \multirow[t]{2}{*}{ Variable } & \multicolumn{2}{|c|}{ Least squares method model } & \multirow{2}{*}{$\begin{array}{l}\text { First-order difference } \\
\text { model } \\
\text { M3 }\end{array}$} \\
\hline & M1 & M2 & \\
\hline Explanatory variable & $\begin{array}{l}\text { Monthly income of } \\
\text { first job }\end{array}$ & $\begin{array}{l}\text { Monthly income of } \\
\text { present job }\end{array}$ & $\begin{array}{l}\text { Monthly income } \\
\text { difference }\end{array}$ \\
\hline \multirow[t]{2}{*}{ Internal interaction } & -.0005 & -.018 & -.003 \\
\hline & $(.007)$ & $(.015)$ & $(.009)$ \\
\hline \multirow[t]{2}{*}{ Outward interaction } & $.024^{*}$ & $.047^{* *}$ & $.028^{* *}$ \\
\hline & $(.009)$ & $(.013)$ & $(.008)$ \\
\hline \multirow[t]{2}{*}{ State-owned unit } & $-.393^{*}$ & -.119 & $-.270^{*}$ \\
\hline & $(.122)$ & $(.103)$ & $(.127)$ \\
\hline \multirow{2}{*}{$\begin{array}{l}\text { Internal interaction } \times \text { state-owned } \\
\text { sector }\end{array}$} & -.001 & .013 & .026 \\
\hline & $(.013)$ & $(.014)$ & $(.019)$ \\
\hline \multirow{2}{*}{$\begin{array}{l}\text { Internal interaction } \times \text { state-owned } \\
\text { sector }\end{array}$} & -.008 & $-.032^{* *}$ & $-.023^{*}$ \\
\hline & $(.011)$ & $(.008)$ & $(.010)$ \\
\hline \multirow[t]{2}{*}{ Seeking job by pulling strings } & $.099^{* *}$ & .008 & .037 \\
\hline & $(.015)$ & $(.049)$ & $(.035)$ \\
\hline \multirow[t]{2}{*}{ Male } & $-.078^{* *}$ & $-.115^{* *}$ & - \\
\hline & $(.013)$ & $(.024)$ & - \\
\hline \multirow[t]{2}{*}{ Age } & .026 & .001 & $.029^{* *}$ \\
\hline & $(.011)$ & $(.011)$ & $(.007)$ \\
\hline \multirow[t]{2}{*}{ Square of age/100 } & .021 & -.132 & $-.029^{*}$ \\
\hline & $(.027)$ & $(.015)$ & $(.010)$ \\
\hline \multirow[t]{2}{*}{ Education level } & $.044^{* * *}$ & $.057^{* * *}$ & $.080^{* * *}$ \\
\hline & $(.004)$ & $(.009)$ & $(.009)$ \\
\hline \multirow[t]{2}{*}{ Party member } & .089 & $.136^{*}$ & $.273^{* *}$ \\
\hline & $(.059)$ & $(.065)$ & $(.062)$ \\
\hline \multirow[t]{2}{*}{ Frequency of changing jobs } & - & .007 & -.011 \\
\hline & - & $(.006)$ & $(.013)$ \\
\hline \multirow[t]{2}{*}{ Unit size/100 } & -.001 & $.036^{* *}$ & .001 \\
\hline & $(.001)$ & $(.007)$ & $(.001)$ \\
\hline \multirow[t]{2}{*}{ Administrative staff } & .083 & $.187^{* *}$ & $.175^{* * *}$ \\
\hline & $(.030)$ & $(.021)$ & $(.026)$ \\
\hline $\begin{array}{l}\text { Category of employment (10 } \\
\text { categories) }\end{array}$ & Yes & Yes & Yes \\
\hline \multirow[t]{2}{*}{ Intercept } & .062 & .730 & $.907^{* *}$ \\
\hline & $(.137)$ & $(.252)$ & $(.229)$ \\
\hline$R$ square & .398 & .233 & .110 \\
\hline Sample size & 2536 & 2536 & 2536 \\
\hline
\end{tabular}

Note: (1) ${ }^{*} p<0.05, * * p<0.01, * * * 00.001$. (2) Values inside the parentheses are standard errors obtained by taking heteroskedasticity robustness and urban cluster robustness into account. (3) "Yes" means that this variable is controlled for in the model. (4) In a difference model, an explanatory variable corresponds to the change value; for specifics, please refer to notes below Tables 3 and 4

$(=0.047-0.032)$. The first-order difference model results show that the effects of variations in outward interaction on income changes in non-state departments are 0.028 and that such a value is only $0.005(=0.028-0.023)$ for those in state-owned sectors. To sum up, the market effects of outward interaction in the state-owned sector are 
significantly weaker than the effects in the non-state sector. By contrast, as far as internal interaction is concerned, no such significant difference exists in the corresponding market effect. Hypothesis 3 mentioned above is thus verified.

\section{Conclusion}

Studies of the labor market of social capitals form an important branch of sociology. However, the majority of the literature focuses on the network of intimacy relationships, such as friends and relatives. The relational network inside the workplace is seldom studied. In this paper, data from JSNET2009 was utilized for empirical analysis on the income effects of occupational income. First, the concept of occupational interaction as social capital was summarized together with the relevant research, so that classifications and measurements about occupational interaction were specifically probed based on previous studies. Second, targeted at the endogeneity problem of accessed social capital effects, the first-order difference method was employed based on an assumption of a fixed effect model to eliminate individual heterogeneity; hopefully, more objective and rigorous judgments can thus be made for labor market effects of occupational interaction. Concerning JSNET2009, data relating to first job and present job were collected in fields of occupational interactions, individual labor market outcomes, and multiple demographic variables. As a result, crucial data foundations were provided for the first-order difference analysis.

During analysis, three hypotheses were put forward. Whether the benchmark difference model was based on a sample size of more than 6000 or a precise difference model based on a sample size of over 2000, our analysis results indicate that both internal and outward interactions play positive roles in determining the income of laborers, with the outward interaction being more important. A more critical effect of outward interaction is its reflection of the important values of heterogeneous social resources (Lin 2008). In addition, this paper also probed the relationship between occupational interaction and degree of marketization. After interaction item analysis, it was found that the interaction item coefficient for outward interaction and the state-owned sector is significantly negative, which signifies that in cities in China, the impact of heterogeneous social resources on income in non-state sectors is stronger than stateowned sectors. Such feature of social capital in the workplace is different from social capital based on personal relationships.

Compared with traditional cross-sectional model results, the casual explanatory power of the analysis and results presented in this paper is stronger; in addition, sample size of the first-order difference is also larger and more robust than in former studies. For example, the empirical studies of Chen et al. (2013, 2014) offers examples of the earliest social capital analysis by means of differential analysis. However, constrained by data size, difference samples in China and Germany only covered 60-70 people, and the corresponding observed values ranged from approximately 130 to 150. Such data was far smaller than that was used in this paper. Our differential study is thus a further expansion of previous analysis. Without doubt, deficiencies still exist in such analysis. First, the factor of urban change is not taken into consideration. Although it is less likely for cities to affect occupational interaction and income simultaneously, cities where individuals live are set to be invariant according to the difference model; in real life, however, the workplaces for first and present jobs may differ. Second, even though 
the factor of individual ability that does not change with time is controlled for, it still cannot be inferred that endogeneity problems have been solved, because some individual heterogeneity may vary with time and such issues need to be tackled by means of instrumental variables (Chen 2012a). Third, our data is derived from eight cities in China; therefore, differences may lie in the marketization degree of metropolis and small- to medium-sized cities. Hence, we hope to take advantage of a counter-factual model to analyze labor market effects of occupational interaction more effectively, based on more data. Meanwhile, we also hope that more attention will be directed towards studying social capital in the workplace.

\section{Endnotes}

${ }^{1}$ The analysis by $\mathrm{Li}$ and $\mathrm{Tu}$ (2011), however, utilizes data from two points in time. Their actual intervals range from 1 week to 1 month; moreover, it is not repeated measurement data. Such data therefore still falls into the category of cross-sectional data, and the problem of reverse causality is thus tackled. But the problem of omitting variables remains unresolved.

${ }^{2}$ In literature on the labor market, individual social capital can be classified according to three major aspects (Lin 1999; Mouw 2003; Chen and Fan 2011). The first aspect is "using contacts". Such studies mainly analyze the impact of contacts used (or not) on individual labor market outcomes. Second, studies on "used social capital" analyze contact users as objects and pay primary attention to promoting the functions of mobilized and utilized resources (e.g., the occupational reputation of a patron) on individual labor market outcomes. The third aspect is about "accessed social capital". Studies that take this perspective focus on the application of quantities and qualities of social resources accessed by respondents.

${ }^{3}$ The New Year Greeting Network (Bainian Wang), which means a network formed when Chinese people participate in an intense round of visiting, gift giving, and feasting with family, friends, colleagues, and neighbors in celebrating Chinese New Year (Bian and Li 2001).

${ }^{4}$ Please note that the term "ectogony" does not mean that the social capital variable is assumed to be exogenous or endogenous; rather, it signifies those concepts given by Manski in his classic article about social interaction (Manski 1993). Sometimes, "ectogony" can also be referred to as "contextual effects". Taking the labor market as an example, if the income of job seekers is impacted by the average earnings of his/her friends, such a phenomenon is known as an endogenous interactive effect; that is, income has an influence on income. In contrast, if the income of a job seeker can be affected by the average education level of his/her friends, this is known as ectogony; that is, income is impacted by other factors (Durlauf 2002). For similar empirical social capital studies, please see Lin and Dumin 1986 and Volker and Flap 1999.

${ }^{5}$ Two-way causality is also a potential source of endogeneity bias. However, the inference that high income leads to more occupational interactions is not supported by relevant theories or empirical studies. Consequently, simultaneity problems are not key points of endogeneity on which this paper focuses.

${ }^{6}$ Bian Yanjie, Director of Institute for Empirical Social Science Research (IESSR) of Xi'an Jiaotong University. 
${ }^{7}$ Due to space limitations, the analysis results for calibrations based on average income by province are not presented in this paper. Those who are interested in these results can contact us for information. We thanks the reviewers for suggestions.

${ }^{8}$ Individual testing is also performed for six child pointers. When these pointers enter the difference model simultaneously, it can be found that the subordinate intercourse of internal interaction and other contacts of outward interaction are significantly positively correlated to income, which verifies our hypotheses. The subordinate intercourse itself of the internal interaction represents seniority instead of social capital. Due to limited space, concrete outcomes are not shown here.

${ }^{9}$ Education levels acquired by the questionnaire are encoded as follows: primary school = 6 years, junior high school $=9$ years, senior high school $=12$ years, professional high school/ technical school/technical secondary school $=13$ years, adult junior college $=14$ years, specialized subject in college $=15$ years, adult undergraduate $=15$ years, undergraduate college $=16$ years, and postgraduate and above $=19$ years.

${ }^{10}$ Concerning the total sample, the average income of laborers in "first job" is 130.94 $\mathrm{RMB}$ on the one hand, and the corresponding standard deviation is 9047.16. As the year of starting the first job for each laborers differs, it is normal to see such an income gap. On the other hand, the average income for the present job is 231.54 RMB for laborers. Incomes have gone up markedly. With a standard deviation of 7802.73, the income gap is rather large.

Authors' contributions

WL and YC conceived and designed the study. YB provided the data and give some critical recommendations. WL and YC wrote the paper and reviewed and edited the manuscript. All authors read and approved the manuscript.

Competing interests

The authors declare that they have no competing interests.

\section{Author details}

${ }^{1}$ School of Social and Behavioral Sciences, Nanjing University, Nanjing University Xianlin Campus, No.163, Xianlin Road, Qixia District, Nanjing City, Jiangsu Province, China. ${ }^{2}$ School of Humanities and Social Sciences, Xi'an Jiaotong University, No. 28 Xianning West Road, Beilin District, Xi'an City, Shaanxi Province, China.

Received: 18 November 2016 Accepted: 20 February 2017

Published online: 03 March 2017

References

Akos, Rona-Tas. 1994. The first shall be last? Entrepreneurship and communist cadres in the transition from socialism American Journal of Sociology 100(1):40-69.

Beaman, Lori A. 2008. Social networks and the dynamics of labor market outcomes: evidence from refugees resettled in the U. S. Northwestern University. Mimeo.

Bian, Yanjie, and Yu Li. 2001. Social network capital of Chinese urban families. Tsinghua Sociological Review 2:1-18.

Bian, Yanjie, and J.R. Logan. 1996. Market transition and the persistence of power: the changing stratification system in urban China. American Sociological Review 61(5):739-758.

Bian, Yanjie, and Wenhong Zhang. 2001. Economic systems, social networks and occupational mobility. Social Sciences In China (2):77-89.

Bian, Yanjie. 2004. Source and functions of urbanites' social capital: a network approach. Social Sciences In China (3):136-146.

Breland, J.W., D.C. Treadway, A.B. Duke, and G.L. Adams. 2007. The interactive effect of leader-member exchange and political skill on subjective career success. Journal of Leadership and Organizational Studies 13(3):1-14.

Burt, R.S. 1992. Structural holes: the social structure of competition. Cambridge: Harvard University Press.

Burt, R.S. 2000. The network structure of social capital. Research in Organizational Behavior 22:345-423.

Cao, Ziwei. 2003. Migrant workers' re-construction of social networks and resource flow in networks. Sociological Studies (3):99-110.

Carroll, G.R., and A.C. Teo. 1996. On the social networks of managers. Academy of Management Journal 39(2):421-440.

Chen, Yunsong. 2012. Village-based networks and wages of rural-to-urban migrants: estimating the causal effects of networks using combined identification strategies. Chinese Journal of Sociology/Shehui 32(4):68-92.

Chen, Yunsong, and Yanjie Bian. 2015. Analyzing the corrosive and differential roles of social eating in political trust: the side effects of Guanxi capital. Chinese Journal of Sociology/Shehui 35(1):92-120. 
Chen, Yunsong, and Xiaoguang Fan. 2010. The endogeneity problem in quantitative analysis: a review of estimating causal effects of social interaction. Chinese Journal of Sociology/Shehui 30(4):91-117.

Chen, Yunsong, and B Volker 2016. Social capital and homophily both matter for labor market outcomes_evidence from replication and extension. Social Networks 45:18-31.

Chen, Yunsong, and Xiaoguang Fan. 2011. Measuring the labor market effects of social capital: a literature review and research strategy of dealing with the endogeneity problem. Sociological Studies (1):167-195.

Chen, Yunsong. 2012. Logic, imagination and interpretation: the application of instrumental variables for causal inference in the social sciences. Sociological Studies (6):192-216.

Chen, Yunsong, Beate Völker, and Henk Flap. 2013. Does using contacts matter: a multi-model replication and extension in non-free market economies. Sociological Studies (3):101-118.

Chen, Yunsong, Beate Völker, and Henk Flap. 2014. Don't contacts matter? The debate on the labor market effect of used social capital and new evidence. Sociological Studies (3):100-121.

Cheng, BS, JL Farh, HF Chang, and WL Hsu. 2002. Guanxi, zhongcheng, competence and managerial behavior in Chinese context. Journal of Chinese Psychology 44(2):151-166.

Cheng, BS, LF Chou, TY Wu, MP Huang, and JL Farh. 2004. Paternalistic leadership and subordinate responses: establishing a leadership model in Chinese organizations. Asian Journal of Social Psychology 7(1):89-117.

Cogliser, CC, and CA Schriesheim. 2000. Exploring work unit context and leader-member exchange: a multi-level perspective. Journal of Organizational Behavior 21(5):487-511.

Cole, M.S., W.S. Schaninger, and S.G. Harris. 2002. The workplace social exchange network: a multilevel, conceptual examination. Group and Organization Management 27(1):142-167.

Dienesch, R.M., and R.C. Liden. 1986. Leader-member exchange model of leadership: a critique and further development. Academy of Management Review 11(3):618-634.

Durlauf, S.N. 2002. On the empirics of social capital. The Economic Journal 112(483):F459-F479.

Han, S.K. 1996. Structuring relations in on-the-job networks. Social Networks 18(1):47-67.

Han, G. 2010. Trust and career satisfaction: the role of LMX. Career Development International 15(5):437-458.

Han, Yi, and Baiyin Yang. 2012. The master-apprentice relationship opening the door to the success of the apprentice in career: an analysis from the viewpoint of the political technology. Management World (6):124-133.

Hao, Mingsong, and Yanjie Bian. 2014. Shaping the structure of network resources: the role of occupational interactions. China Studies 18(2):110-128.

Kim, Harris. 2001. Social capital, embedded status, and the endorsement effect. Paper prepared for the SSRC workshop on "Corporation as a Social Institution, Institute of Industrial Relations", UC Berkeley (May 2001).

Law, K.S., C.S. Wong, D. Wang, and L. Wang. 2000. Effect of supervisor-subordinate Guanxi on supervisory decisions in China: an empirical investigation. International Journal of Human Resource Management 11(4):751-765.

Lazega, E., and M. van Duijn. 1997. Position in formal structure, personal characteristics and choices of advisors in a law firm: a logistic regression model for dyadic network data. Social Networks 19(4):375-397.

Li, Peilin. 1996. Social network of rural migrants in China. Sociological Studies 50(4):138-148.

Li, Yanping, and Tu Yidong. 2011. Does high LMX quality benefit subordinate's career success? A moderated mediation study. Acta Psychologica Sinica 43(8):941-952.

Liang, Yucheng. 2010. Is social capital and social networks useless? Sociological Studies (5):50-82.

Lin, N. 1995. Local market socialism: local corporatism in action in rural China. Theory and Society 24(3):301-354.

Lin, N. 1999. Building a network theory of social capital. Connections 22(1):28-51.

Lin, N. 2008. A network theory of social capital. In The handbook of social capital, ed. Dario Castiglione, Jan van Deth, and Guglielmo Wolleb. Oxford and New York: Oxford University Press.

Lin, N., and M. Dumin. 1986. Access to occupations through social ties. Social Networks 8(4):365-385.

Liu, Linping. 2001. Utilization of Guanxi (ties) in immigrant groups-a case study of Pingjiang village in Shenzhen. Social Sciences In China (5):112-124.

Liu, Jun, Jiwen Song, and Wu Longzeng. 2008. Antecedents of employee career development: an examination of politics and Guanxi. Acta Psychologica Sinica 40(2):201-209.

Manski, C.F., 1993. Identification of endogenous social effects: The reflection problem. The Review of Economic Studies 60(3):531-542.

McPherson, M.J., L. Smith-Lovin, and J.M. Cook. 2001. Birds of a feather: homophily insocial networks. Annual Review of Sociology 27(1):415-444.

Meverson, E.M. 1994. Human capital, social capital and compensation: the relative contribution of social contacts to managers' incomes. Acta Sociologica 37(4):383-399.

Mouw, T. 2003. Social capital and finding a job: do contacts matter? American Sociological Review 68(6): 868-898.

Mouw, T. 2006. Estimating the causal effect of social capital: a review of recent research. Annual Review of Sociology 32:79-102.

Munshi, K. 2003. Networks in the modern economy: Mexican migrants in the US labor market. The Quarterly Journal of Economics 118(2):549-599.

Nee, Victor. 1989. A theory of market transition: From redistribution to markets in state socialism. American Sociological Review (5):663-681.

Ng, T.W.H., L.T. Eby, K.L. Sorensen, and D.C. Feldman. 2005. Predictors of objective and subjective career success: a meta-analysis. Personnel Psychology 58(2):367-408.

Peng, M.W., and P.S. Heath. 1996. The growth of the firm in planned economies in transition: institutions, organizations, and strategic choice. Academy of Management Review 21(2):492-528.

Podolny, J.M., and J.N. Baron. 1997. Resources and relationships: social networks and mobility in the workplace. American Sociological Review 62(5):673-693.

Ruan, Danqing, Lu Zhou, Peter M Blau, and Andrew G Walder. 1990. A preliminary analysis of the social networks of residents in Tianjin with a comparison to social networks in America. Social Sciences in China (3):68-89

Scandura, T.A., and C.A. Schriesheim. 1994. Leader-member exchange and supervisor career mentoring as complementary constructs in leadership research. Academy of Management Journal 37(6):1588-1602. 
Schriesheim, C.A., L.L. Neider, and T.A. Scandura. 1998. Delegation and leader-member exchange: main effects, moderators, and measurement issues. Academy of Management Journal 41(3):298-318.

Sparrowe, R.T., and R.C. Liden. 2005. Two routes to influence: integrating leader-member exchange and social network perspectives. Administrative Science Quarterly 50(4):505-535.

Völker, B., and H. Flap. 1999. Getting ahead in the GDR social capital and status attainment under communism. Acta Sociologica 42(1):17-34.

Walder, A.G. 1995. Local governments as industrial firms: an organizational analysis of China's transitional economy. American Journal of Sociology 101(2):263-301.

Wayne, S.J., R.C. Liden, M.L. Kraimer, and I.K. Graf. 1999. The role of human capital, motivation and supervisor sponsorship in predicting career success. Journal of Organizational Behavior 20(5):577-595.

Westwood, R.I, and A. Chan. 1992. Head-ship and Leadership. In Organizational behavior: a Southeast Asian perspectives, ed. R.I. Westwood. Hong Kong: Longman.

Yakubovich, V. 2005. Weak ties, information, and influence: how workers find jobs in a local Russian labor market. American Sociological Review 70(3):408-421.

Zhang, Shun, and Cheng Cheng. 2012. Market reforms and the income effects of social network capital. Sociological Studies (1):130-151.

Zhang, Wenhong. 2011. Social network analysis and social capital studies: 1980-2000. Jianghai Academic Journal (2): 104-112; (3):96-116.

Zhang, Wenhong, Peiliang Li, and Danqing Ruan. 2004. Stratum construction of social networks of urban dwellers. Sociological Studies (6):1-10.

Zhao, Yandong. 1998. The theory of social capital: a review. Social Sciences Abroad (3):19-22.

Submit your manuscript to a SpringerOpen ${ }^{\circ}$ journal and benefit from:

- Convenient online submission

- Rigorous peer review

- Immediate publication on acceptance

- Open access: articles freely available online

- High visibility within the field

Retaining the copyright to your article

Submit your next manuscript at $\boldsymbol{\nabla}$ springeropen.com 